\title{
Modelling burned area in Africa
}

\author{
V. Lehsten ${ }^{1}$, P. Harmand ${ }^{2}$, I. Palumbo ${ }^{3, *}$, and A. Arneth ${ }^{1}$ \\ ${ }^{1}$ Division of Physical Geography and Ecosystems Analysis (ENES), Department of Earth \\ and Ecosystem Sciences, Lund University, Sweden \\ ${ }^{2}$ Institut für Mathematik, Universität Oldenburg, Germany \\ ${ }^{3}$ Department of Geography, University of Leicester, UK \\ * currently at: DG Joint Research Centre - European Commission, Ispra, Italy
}

Received: 18 February 2010 - Published in Biogeosciences Discuss.: 10 June 2010

Revised: 7 September 2010 - Accepted: 27 September 2010 - Published: 20 October 2010

\begin{abstract}
The simulation of current and projected wildfires is essential for predicting crucial aspects of vegetation patterns, biogeochemical cycling as well as pyrogenic emissions across the African continent. This study uses a data-driven approach to parameterize two burned area models applicable to dynamic vegetation models (DVMs) and Earth system models (ESMs). We restricted our analysis to variables for which either projections based on climate scenarios are available, or that are calculated by DVMs, and we consider a spatial scale of one degree as the scale typical for DVMs and ESMs. By using the African continent here as an example, an analogue approach could in principle be adopted for other regions, for global scale dynamic burned area modelling.

We used 9 years of data (2000-2008) for the variables: precipitation over the last dry season, the last wet season and averaged over the last 2 years, a fire-danger index (the Nesterov index), population density, and annual proportion of area burned derived from the MODIS MCD45A1 product. Two further variables, tree and herb cover were only available for 2001 as a remote sensing product. Since the effect of fires on vegetation depends strongly on burning conditions, the timing of wildfires is of high interest too, and we were able to relate the seasonal occurrence of wildfires to the daily Nesterov index.

We parameterized two generalized linear models (GLMs), one with the full variable set (model VC) and one considering only climate variables (model C). All introduced variables resulted in an increase in model performance. Model VC cor-
\end{abstract}

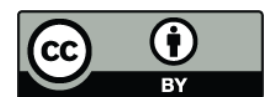

Correspondence to: V. Lehsten (veiko.lehsten@nateko.lu.se) rectly predicts the spatial distribution and extent of fire prone areas though the total variability is underrepresented. Model $\mathrm{VC}$ has a much lower performance in both aspects (correlation coefficient of predicted and observed ratio of burned area: 0.71 for model VC and 0.58 for model C). We expect the remaining variability to be attributed to additional variables which are not available at a global scale and thus not incorporated in this study as well as its coarse resolution. An application of the models using climate hindcasts and projections ranging from 1980 to 2060 resulted in a strong decrease of burned area of ca. $20-25 \%$. Since wildfires are an integral part of land use practices in Africa, their occurrence is an indicator of areas favourable for food production. In absence of other compensating land use changes, their projected decrease can hence be interpreted as a indicator for future loss of such areas.

\section{Introduction}

Wildfires are a global phenomenon directly affecting vegetation temporal and spatial patterns, local and global atmospheric chemistry, and human populations inhabiting the affected areas. Globally, the African continent has the highest amount of annual burned area (Roy et al., 2008) with extensive wildfire activities in African savannas tracing back through the Quaternary period (Bird and Cali, 1998). Over the (mostly low industrialized) African continent, the amount of pyrogenically released carbon is estimated to be of the same order of magnitude as the carbon released by fossil fuel burning (Williams et al., 2007). Not only the pyrogenic

Published by Copernicus Publications on behalf of the European Geosciences Union. 
carbon release is of interest (e.g. for global circulation models, GCMs and Earth System models; ESMs) but also the fire-feedback on vegetation structure and hence biogeochemical cycling. Dynamic vegetation models (DVMs; Arneth et al., 2010b) such as LPJ-GUESS (Smith et al., 2001) simulate vegetation and its atmospheric exchange depending on historic and projected climate data, and in fire-prone environments their results rely strongly on the fire model used (Arneth et al., 2010b).

Some DVM studies investigating the effects of wildfires on vegetation and emissions have used either remotely sensed burned area data (van der Werf et al., 2006; Lehsten et al., 2009) or a dynamic mechanistic burned area model derived from theoretical considerations (Thonicke et al., 2010; Arneth et al., 2010a). The former can only be applied for periods in which remote sensing products are available; the latter is appropriate to analyse past and future changes in fire regimes. Information on the environmental variables relevant for the analysis of wildfire regimes is only available at very different temporal and spatial scales. This has to be taken into account for the design of the study. For instance, slope, a variable with a high spatial variability might be neglected at larger scale leading to an assumed mean value of zero. On the other hand, the common assumption of a mean value over a typical gridcell of the available meteorological data is highly problematic for other variables. This is especially the case for wind speed which affects fire development, spread and intensity and varies strongly at a local scale. It is even influenced by the fire itself due to uplift, given a sufficiently large fire. Mechanistic burned area models derived from applications of fire spread models require the parameterisations of some important processes depending on highly uncertain variables (like horizontal wind speed, fire travel in fragmented landscape, etc.) and statistical assumptions for other parts of the calculation (like the relationship between population density and human-driven ignitions). These uncertainties are amplified by subsequent simulations of fire spread.

Our study seeks to parameterise a statistical model for the prediction of burned area based on its major controlling factors. We use remotely sensed burned areas combined with climate and population density data to optimise a statistical model for the prediction of wildfire activity. Despite its importance for climate change assessments, atmospheric composition and ecology, the analysis of the factors controlling wildfires is at a relatively early stage especially at continental to global scale. This is partly due to the lack of multi-annual high resolution remote sensing data of burned areas until recently (Roy et al., 2010). Though burned area models are of high interest in themselves, they are only applicable to DVMs or ESMs if they are restricted to climate and socio-economic variables with a historical or future projected global coverage at a spatial scale typical for these models (i.e. between $0.25^{\circ}$ and $1^{\circ}$ ), and if they use a model structure that can be linked to the dynamic terrestrial models.
Here we analyze the relationship between annual burned ratio, climatic drivers, tree and grass cover fraction and population density. The resulting generalized linear model for burned area is applicable for use in Dynamic vegetation models or Earth system models. After demonstrating the performance of the model using recent climate data, we also apply it to climate change projections under the SRES A2 and B1 scenarios. While Global climate models deliver projections of climate variables, they do not provide estimates for changes in tree and herb cover, unless they are linked to a DVM. We included these two variables in our analysis since previous studies (e.g. Archibald et al., 2009), have shown vegetation canopy structure to be an important determinant of wildfires and because these dynamically changing structural properties of ecosystems are commonly estimated by DVMs. We simulate total burned area of Africa from 1980 to 2060 using two burned area models, one accounting for climate and vegetation related variables and a second one with a reduced variable set containing only climate related variables.

\section{Methods}

\subsection{Data selection}

For the development of the generalized linear model, we considered the period from 2000 to 2008, resulting in eight "fire years" (see below). The burned area data were separated into three sets: a training dataset, a validation dataset and a dataset only used to evaluate the spatial patterns of the prediction. The training dataset contained all data except for a longitudinal band from $20^{\circ} \mathrm{E}-30^{\circ} \mathrm{E}$ over the whole continent (Fig. 1) and all data from the year 2007 and was used to estimate the model parameters. The validation dataset contained this left-out longitudinal band from $20^{\circ} \mathrm{E}-30^{\circ} \mathrm{E}$ (Fig. 1) for all years and was used to calculate the correlation coefficients (R-values; see below). A third dataset, containing only the year 2007 and covering the full continent was used to evaluate the spatial performance of the model and to display the spatial patterns of the differences between model predictions and data at continental scale.

When testing the relationship between spatially distributed variables it is common practice to separate the data randomly between training and validation data, and to repeat the procedure of generating training and evaluation data to generate a large number of models. This allows evaluating the variation of performance among the estimated models. However, in our study we decided to use a single, spatially and temporally predefined validation dataset because a bootstrapping procedure of randomly assigning data points to either the training or validation dataset results in different model parameters for each randomised training and evaluation data set. Since our focus lies on the estimation of these model parameters for further application we aimed for a single model, instead of a 


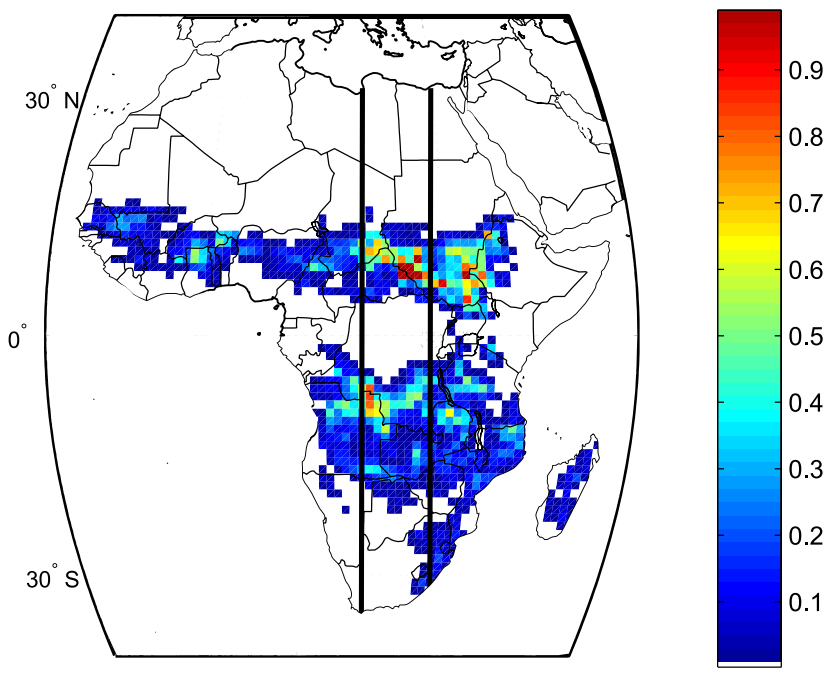

Fig. 1. Mean annual fraction of area burned, averaged over all investigated years from 2000-2007. Data from grid cells located outside the two bold meridian lines were used as training data to estimate the model parameters (except for the data for the year 2007). The data from grid cells between the two meridians were only used to estimate the R-values.

range of models resulting from randomised data sets. Therefore we choose the validation data in a way that it covers as much variation as possible with respect to the variables by using a cross continental longitudinal band. By assigning data from all years to the validation data, instead of using e.g. a single year as validation we assured that no spatial location that contributed to the training data is used in the validation dataset.

\subsection{Burned area}

Since the fire seasons are different in the northern and Southern Hemisphere, burned fractions for both hemispheres were calculated for different time periods. The "fire year" was set to last from the 1 of April until the 31 of March in the Northern Hemisphere, whereas in the Southern Hemisphere it spans from 1 of November to 31 of October (for details see Arneth et al., 2010a). While fire seasons are defined as times with considerable amounts of burned area (see Results section), we separated the data into "fire years" spanning a whole year, to account not only for the actual fire season (called dry season in the remaining parts) but also the preceding wet season, see below. This allowed us to pool Northern and Southern Hemisphere Africa into a single dataset.

We used the MCD45 burned area product (Roy et al., 2008). These burned area maps come as monthly data with a $500 \mathrm{~m}$ spatial resolution and were combined into annual datasets for the period 2000-2008. The MCD45 product is known to underestimate the total burned area (Roy, 2009) therefore we used the lowest quality stage of the burned area data, which has the highest level of detection of burned area (and also the highest level of incorrectly detected burned areas). All pixels for which the data was insufficient to provide clear classification, i.e. leading to a value of 10000 in the burn-date array of the MODIS product were discarded. Since we used a one degree horizontal grid for our analysis, information on the fire occurrence based on the original $500 \mathrm{~m}$ pixels was transformed to a burned area fraction (also called burned area ratio) in each one degree cell. The annual burned areas (Figs. 1 and 3a) were derived from the monthly maps without specifically accounting for whether a pixel was classified as "burned" one or more times in the same "fire year". The annual "burn fraction" value for each grid cell was then derived by calculating the ratio between the number of pixels classified as "burned" over the 12-month period and the total number of valid pixels within the same cell. In that way, we assumed indirectly that the pixels that were not classified in the MODIS product experience the same fire frequency as the classified pixels. This procedure increases the burned area compared to the standard approach of only counting valid pixels (e.g. Giglio et al., 2010). We performed this procedure for two reasons: firstly, in regions that experience a relatively long wet period, for example western Africa, the MODIS product is known to miss fires due to prolonged cloud cover. In these areas, the increase will be strongest. Secondly, the MODIS burned area product underestimates the burned area even under good visibility conditions, see below.

The MODIS MCD45 product derives the burned area from changes in reflectance values, by contrast to products based on active fire data counts (i.e. remotely sensed active fires) which can be converted into burned area, e.g. based on the fractional tree cover (e.g. Pechony and Shindell, 2009). We consider the use of burned area data to be more reliable than converted active fire count data since the time period for potential detection of burned area is longer. Active fire data only takes into account fires occurring during the satellite overpass in cloud-free conditions. Therefore polar-orbiting satellites can only provide partial information on the fire activity. In Africa this is particularly relevant since fires usually last only few hours or less (though some large fires might last for several days in the absence of fire breaks) and as a consequence the non-detection rate of fires in hot spot products is relatively large. A recent evaluation exercise (Roy and Boschetti, 2009) of the burned area products L3JRC (Tansey et al., 2008), GlobCarbon (Simon et al., 2004) and MODIS MCD45 (Roy et al., 2008) against classified $5 \mathrm{~km} \times 5 \mathrm{~km}$ Landsat scenes of southern Africa found highest level of agreement for the MODIS product, resulting in a correlation coefficient $R=0.86\left(R^{2}=0.75\right)$ and a slope of 0.75 (Roy and Boschetti, 2009).

\subsubsection{Tree and herb cover}

Fuel estimation in savannah regions from remotely sensed data is not well established. Mbow et al. (2004) used spectral parameters for wetness, brightness and greenness as a 
proxy, which can be derived from satellite data but these parameters are normally not calculated by DVMs. We therefore prefer the use of fractional cover of trees and herbs, as variables that can both be assessed from remotely sensed data and calculated by terrestrial models. Grassy vegetation provides in combination with trees the fuel (mainly litter) required for a wildfire to burn. The relative woody and herbaceous cover is expected to influence wildfires in a number of ways in African savannas. Low tree cover indicates overall dry conditions with low fuel production and infrequent fires since the fuel needs to accumulate over several years, whereas a high tree cover can be linked to moist and therefore unfavourable burning conditions. Savannas as well as natural and semi-natural grasslands in the semi-arid tropics are particularly fire prone due to sufficient fuel production, combined with the use of fire as a common landscape management tool to enhance grass re-growth for grazers and to avoid shrub encroachment (Saarnak, 2001; Mbow, 2000; Hough, 1993). Archibald et al. (2009) in their investigation of drivers of burned area found tree cover to have the highest predictive value.

For the development of our burned area regression model, woody and herbaceous fractional cover data were generated by up-scaling the MODIS Vegetation Continuous Fields product (VCF; Hansen et al., 2003). This product provides information of the tree, herbaceous vegetation and bare ground fractions at $500 \mathrm{~m}$ resolution for the year 2001. Since the three fractions sum up to a maximum of $100 \%$, no information is available on possibly overlapping layers of vegetation (i.e., forest understorey). However, most savannah areas, which are burning frequently, have no closed canopies like rainforests, making the detection of understorey grasses possible for the satellite. Though tree and herb cover are expected to change over the course of time, to our knowledge there is no continuous product available for the investigated time period. Given that the data are aggregated to one degree spatial resolution, we expect, only a low year to year variability at this scale at least over the time period of our analysis. However, over the time period used to project the burned area, this ratio is expected to change considerably.

\subsubsection{Population density}

The vast majority of burned area is ignited by humans under present-day conditions (Saarnak, 2001) which provides the basis of using population density as a viable proxy for the analysis of fire-regimes. Venevsky et al. (2002) used an exponential function to relate the number of ignitions by humans to population density. This steadily increasing relationship is subsequently multiplied with a spatially explicit factor of human ignition potential (ignitions per person per day; derived from remote sensing data) which takes into account effects of urbanity and typical land use practices. This approach has been further developed by Thonicke et al. (2010) who applied a uni-modal shaped relationship between popu-
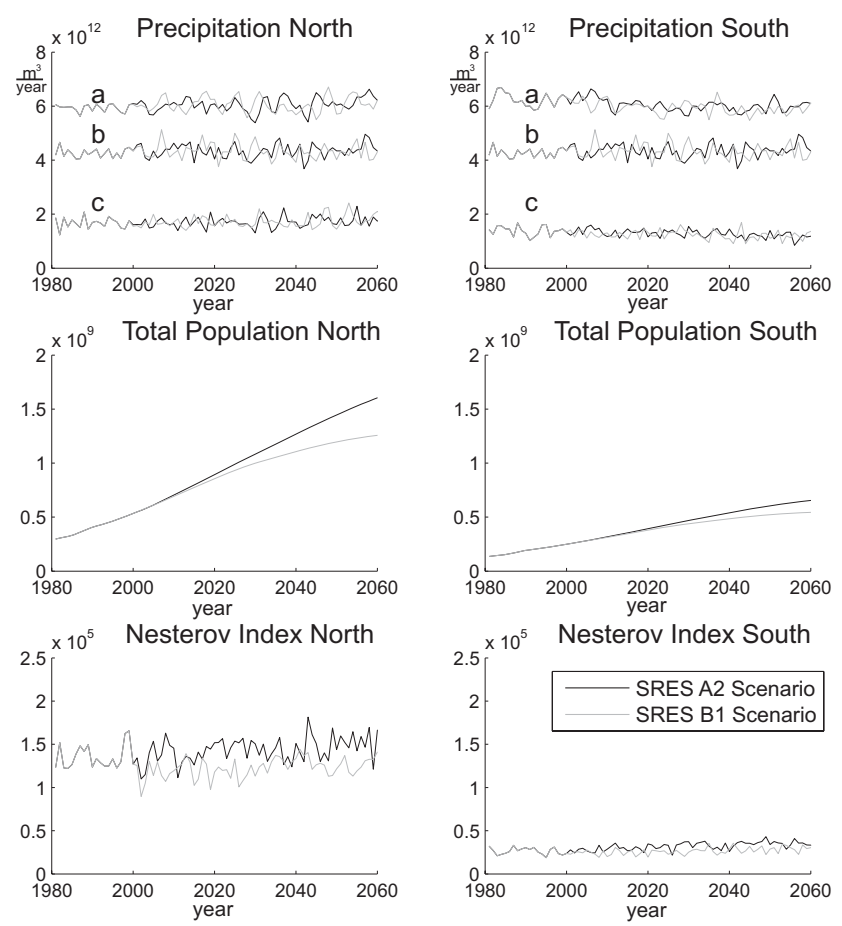

Fig. 2. Simulated climate and population variables used to project the burned area until the year 2060, taken from the two SRES storylines A2 and B1 and ECHAM climate model projections. The time period from 1980 to 2000 is calculated from the control simulation of the 20th century and is therefore similar in both scenario runs. For details of the used data sets see the Methods section. Upper panels: total precipitation: lines a: mean annual precipitation over the last 4 seasons (covering 2 years); lines b: total precipitation during the wet season; lines c: total precipitation during the dry season; middle panels: total population, lower panels Nesterov index, mean of maximum values of each year.

lation density and number of potential ignitions reflecting the fact that a certain minimum population density is required in order to maintain land use systems which can make use of fire as a landscape management tool. Decreased ignitions at high population densities reflect active fire suppression and urbanisation that both limit fire occurrence and spread.

For our analysis we used the dataset for population density (raster dataset; resolution $5 \times 5$ arc min) provided from the FAO available for the years 2000 and 2005 and as a projection for 2010 (Healy, 2008). We scaled the data to one degree latitude and longitude and interpolated intermediate years linearly. For the application of the parameterised model into the future we used the gridded population projection from Bengtsson et al. (2006) for the two SRES storylines B1 and A2 (Fig. 2).

\subsubsection{Precipitation}

Precipitation is a main driver of net primary production and thus of fuel load in semi-arid regions. Several aspects of 
precipitation are potentially influencing wildfires: Spessa et al. (2005) as well as Lehsten et al. (2009) found a uni-modal relationship between total precipitation sum and the amount of burned area. Harris et al. (2008) found a strong relationship between the burned area and the precipitation of the preceding wet season in northern Australia. As suggested by Van Wilgen (2004) we also tested the influence of the mean precipitation of the last two dry and wet seasons since there seems to be a certain time period required for the vegetation to grow and produce litter for fuel build up sufficient to maintaining a wildfire.

Based on the originally daily TRMM precipitation data (data set 3B43, Kummerow et al., 1998) we generated three precipitation input parameters, each reflecting our fire year definition. Total precipitation during the potential dry season (NHA: October-March, SHA: May-October), capturing burn conditions over the dry period; total precipitation during the potential wet season (NHA: April-September; SHA: November-April), as the period that determines the potential fuel load of the given year; and average precipitation over the last two wet and dry seasons, representing potential fuel accumulation.

\subsubsection{Nesterov index}

In addition to ignition sources and a certain amount of fuel, an obligatory condition for wildfire development is the sufficient dryness of the fuel. Fuel dryness is related to the Nesterov fire-hazard-index (short Nesterov index; Nesterov, 1949; Thonicke et al., 2010). Being originally developed for boreal areas, this daily (d) index $\left(N e s t_{\mathrm{d}}\right)$ depends on daily precipitation $\left(p_{\mathrm{d}}\right)$ and the mean and dewpoint temperatures $\left(t_{\text {mean }}\right.$ and $\left.t_{\mathrm{dew}}\right)$. For days with precipitation below $3 \mathrm{~mm}$ the index is computed as in Eq. (1) and it is (re)set to zero if the daily precipitation is above $3 \mathrm{~mm}$ (Eq. 2). Reflecting its derivation in northern regions, the Nesterov index is also reset to zero if the temperature drops below zero degrees Celsius. Since there are regions in Africa where neither low temperature nor daily precipitation above $3 \mathrm{~mm}$ occur over several years, we limited this statistic to a maximum value of $2 \times 10^{5}$ to avoid accumulation to unreasonably high values (Eq. 3).

$$
\begin{aligned}
& \text { Nest }_{\mathrm{d}}=\left(t_{\text {mean }}-t_{\mathrm{dew}}\right) t_{\text {mean }}+N e s t_{\mathrm{d}-1} \quad \text { if } p_{\mathrm{d}}<3 \mathrm{~mm} \\
& \text { Nest }_{\mathrm{d}}=0 \quad \text { if } p_{\mathrm{d}} \geq 3 \mathrm{~mm} \\
& \text { Nest }_{\mathrm{d}}=2 \times 10^{5} \quad \text { if } \text { Nest }_{\mathrm{d}} \geq 2 \times 10^{5}
\end{aligned}
$$

In boreal areas a value of $300-1000$ is considered to indicate a low fire danger, from 1001 to 4000 the fire danger is moderate and all values above 4000 are considered to indicate extreme fire danger. For African conditions, the generally much higher temperatures lead to a stronger increase in the index compared to boreal parts of the world, thus fire danger scales differently to the index. However, our derived models are only applied to the African continent where precipitation is the major environmental driver for fire, not temperature, and the Nesterov index still reflects a valid relative measure of dryness which can be related to wildfire occurrence.

Since the dewpoint temperature was not available in the climate datasets, we approximated it as follows using the relative humidity:

$t_{\text {dew }}=\frac{237.7^{\circ} \mathrm{C}\left(\frac{17.271 t_{\text {mean }}}{237.7^{\circ} \mathrm{C}+t_{\text {mean }}}+\ln \left(h_{\mathrm{r}}\right)\right)}{17.271-\frac{17.271 t_{\text {mean }}}{237.7^{\circ} \mathrm{C}+t_{\text {mean }}}+\ln \left(h_{\mathrm{r}}\right)}$

with $t_{\text {mean }}$ and $t_{\text {dew }}$ being the mean and dewpoint temperatures and $h_{\mathrm{r}}$ being the relative humidity ranging from 0 to 1 (Foken, 2003, p. 43) .

The Nesterov index varies daily. In the first part of our statistical analysis we used the maximum value over each grid cell reached in each "fire year", while for the estimation of the seasonal occurrence of wildfires we applied an analysis based on the daily varying values. A Hovmöller plot was used to illustrate the average Nesterov index over the course of the year per longitudinal band of one degree width visually. For all cells that experienced a higher burned area ratio than $0.1 \%$ (i.e. 0.001 ), we also statistically related the sum of burned area ratios to the corresponding Nesterov index.

\subsection{Data analysis}

All input data were re-gridded to one degree resolution. Logistic regression models with quadratic terms (generalized linear models; GLMs; Eq. 5) were then generated by pooling all 8 "fire years" of data. These models evaluate the probability of a certain event (the area being burned) in relation to a certain variable (e.g. ratio of tree cover), or combinations of variables. In cases where the relationship between burned area and the investigated variable was asymmetrical (skewed) we used the logarithm of the variable as input (e.g. burned area vs. population density; Fig. 3f). For each one degree cell the amount of data used to estimate the parameter is equal to the number of successfully classified $500 \mathrm{~m} \mathrm{MCD} 45$ pixels. We calculated a correlation coefficient (R-value) for each parameterisation by correlating the observed burned areas to the predicted values derived from the model estimation for the evaluation dataset.

Two models were parameterised: model VC derived from the full set of variables (including vegetation and climate related variables) and model $\mathrm{C}$ derived only from the climate variables not containing tree and herb cover.

\subsubsection{Model choice: Baysian Information Criterion (BIC)}

Clearly, the generalized linear regression analysis as presented here must take into consideration some inevitable short-comings: the sum of tree cover and herb cover can 

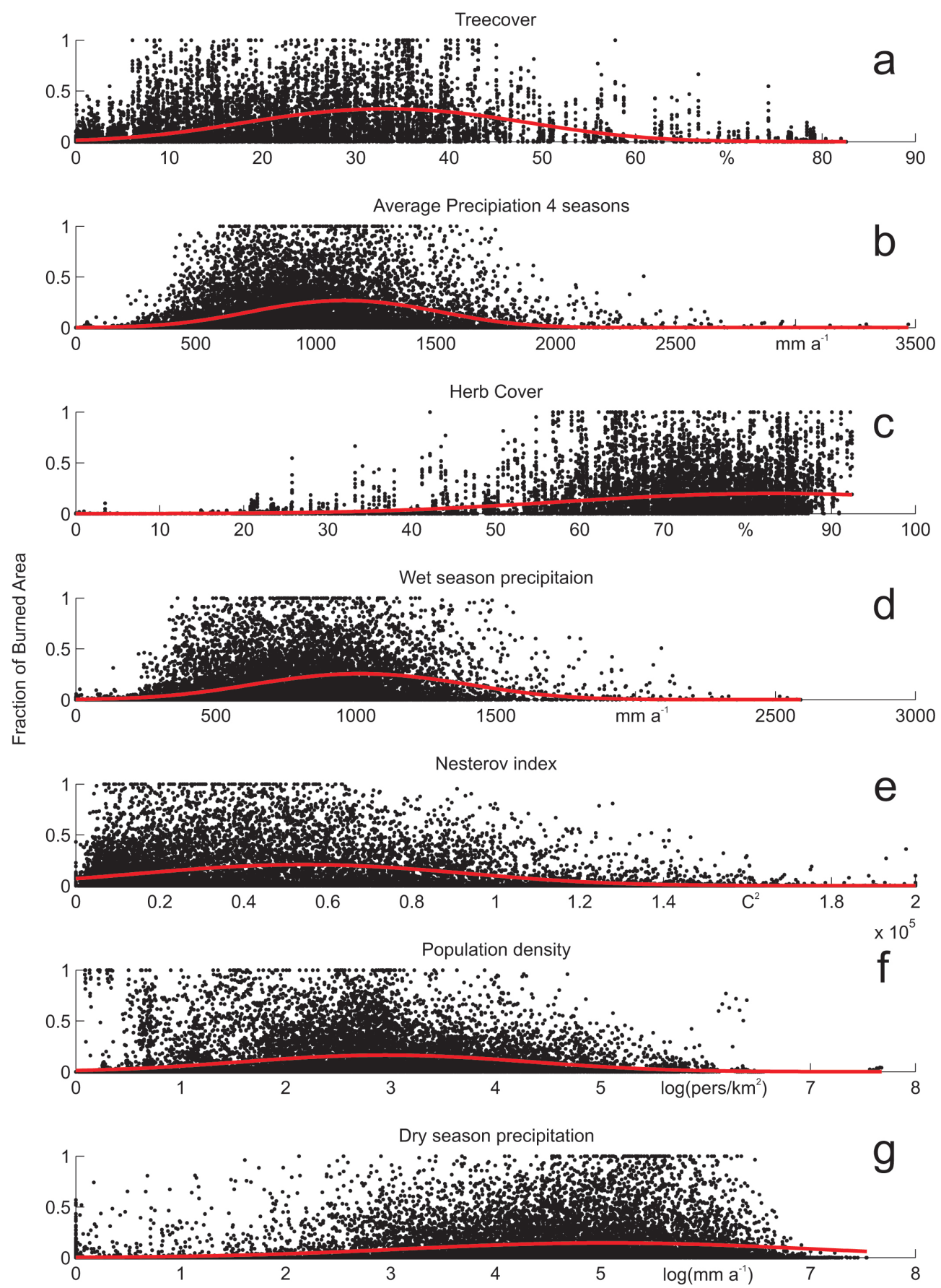

Fig. 3. Response of burned area to the variables tree and herb cover, precipitation (average over the last four seasons, last wet season, last dry season) and population density. The correlation coefficients as well as the model parameter for each variable are listed in Table 1.

result only in a maximum of $100 \%$. All the precipitation variables can be expected to exert a certain degree of codependence, spatially as well as temporally. In fact, all incorporated variables are to a certain degree correlated with each other. Due to the low rate of industrialization, the population density depends on the ability of the surrounding area to produce food, which again is directly related to the annual rainfall. Since all variables quantify different aspects of the grid cell which potentially influence the burned area we decided to base the decision to include or discard them not on their level of correlation but on the improvement of the final model. 
Table 1. Parameterisation of model VC. Correlation coefficient (R-value) of all models with variables used as single predictors; constant linear and squared coefficients of the single variable models and of model VC. The constant term for the final model is -10.06 . The abbreviations $v, l$ and $s$ are used in Eq. (5).

\begin{tabular}{|c|c|c|c|c|c|c|}
\hline Model variables $(v)$ & $\begin{array}{l}\text { Corr. coeff. } \\
\text { in single var. } \\
\text { model }\end{array}$ & $\begin{array}{l}\text { Constant term } \\
\text { in single var. } \\
\text { model }(a)\end{array}$ & $\begin{array}{l}\text { Linear coeff. } \\
\text { in single var. } \\
\text { model }(l)\end{array}$ & $\begin{array}{l}\text { Squared coeff. } \\
\text { in single var. } \\
\text { model }(s)\end{array}$ & $\begin{array}{r}\text { Linear coeff. } \\
\text { in final } \\
\text { model }(l)\end{array}$ & $\begin{array}{r}\text { Squared coeff. } \\
\text { in final } \\
\text { model }(s)\end{array}$ \\
\hline Mean Precipitation last 4 seas. [mm] & 0.49 & -6.55 & $1.00 \times 10^{-2}$ & $-3.92 \times 10^{-6}$ & $3.22 \times 10^{-3}$ & $-1.29 \times 10^{-6}$ \\
\hline Herb-cover [ratio] & 0.43 & -8.13 & $1.63 \times 10^{-1}$ & $-8.20 \times 10^{-4}$ & $8.78 \times 10^{-3}$ & $7.41 \times 10^{-4}$ \\
\hline Precipitation Rain-season [mm] & 0.46 & -5.76 & $9.51 \times 10^{-3}$ & $-4.08 \times 10^{-6}$ & $-3.69 \times 10^{-4}$ & $2.66 \times 10^{-7}$ \\
\hline $\log ($ Precipitation Dry-season $[\mathrm{mm}])$ & 0.26 & -5.72 & 3.62 & $-6.89 \times 10^{-1}$ & $-4.43 \times 10^{-1}$ & $2.66 \times 10^{-1}$ \\
\hline
\end{tabular}

To evaluate whether the incorporation of additional parameters in the model increased the quality of the model or simply increased the correlation factor due to over-fitting we used the Bayesian Information Criterion. This criterion is known to penalize additional parameters stronger than the Akaike criterion (Schwarz, 1978). The model with smallest BIC is considered the best. To test whether the BIC values differ significantly, we used a bootstrapping procedure resampling the dataset repeatedly $10^{3}$ times, and subsequently estimating all model parameters. BIC values for each variable combination were then compared with the variable combination containing one variable more using the Wilcoxon signed rank test at the 5\% significance level. Variables were considered to significantly improve the model performance if the BIC values decreased significantly.

\subsection{Model application - climate scenarios}

To test the applicability of the parameterised model, and to assess the expected trend of burned area in the African continent, we applied the model using simulated climate data based on the two SRES storylines A2 and B1, and the ECHAM climate model. We used the 6 hourly values provided from the World Data Center for Climate i.e. the experiments EH5-T63L31_OM_20C3M_1_6H, EH5T63L31_OM-GR1.5L40_A2_1_6H and EH5-T63L31_OMGR1.5L40_B1_1_6H (Roeckner, 2005) to calculate the annual variables (see Fig. 2). We combined the first dataset containing simulated climate data for the 20th century with each of the other two which contained the projected climate to obtain two time series spanning from 1980 until 2060 and calculated the resulting total burned area. We parameterised two sub-models, one with (model VC) and one without (model C) tree and herb cover. For the projection of burned area using model VC we assumed the tree and herb cover to be fixed over the simulation period.

\section{Results}

The relationships that emerged between each of the investigated variables and the fraction of burned area are displayed in Fig. 3. All variables showed a uni-modal response although for some of them logarithms were taken in order to make the response more symmetric. The p-values of all GLMs, testing the difference to zero for all model parameter of the modelled response (red lines) were below $10^{-4}$, indicating a uni-modal rather than a linear distribution of the data.

To assess the explanatory value of each descriptive variable we used the correlation coefficients (R-values) of the single variables (Table 1) using the parameters estimated from the training data, and calculating the correlation between the predicted and the remotely sensed burned area using the validation dataset. After estimating the fit of the GLMs using only one variable, we generated cumulative GLMs adding one variable after the other and calculated BIC values. A test of difference revealed that each variable increased the performance of the cumulative model. The final GLM, containing all variables (model VC) resulted in an Rvalue of 0.71 . When only climate related variables are considered (model C), the R-value was reduced to 0.58. Correlating the predicted values of the training datasets with the observed values of the training dataset using model VC results in an R-value of 0.74 (model C: 0.60 ). This increases our confidence in the selection procedure by showing that the training area well represents the evaluation area with respect to the relationship between burned area and considered variables.

For the variables dry season precipitation and population density we used the natural logarithm instead of the actual value to link to burned area $\left(b_{\mathrm{a}}\right)$ in the form of:

$$
b_{\mathrm{a}}=\frac{1}{1+e^{-\left(a+\sum_{i=1}^{7} l_{i} v_{i}+s_{i} v_{i}^{2}\right)}}
$$



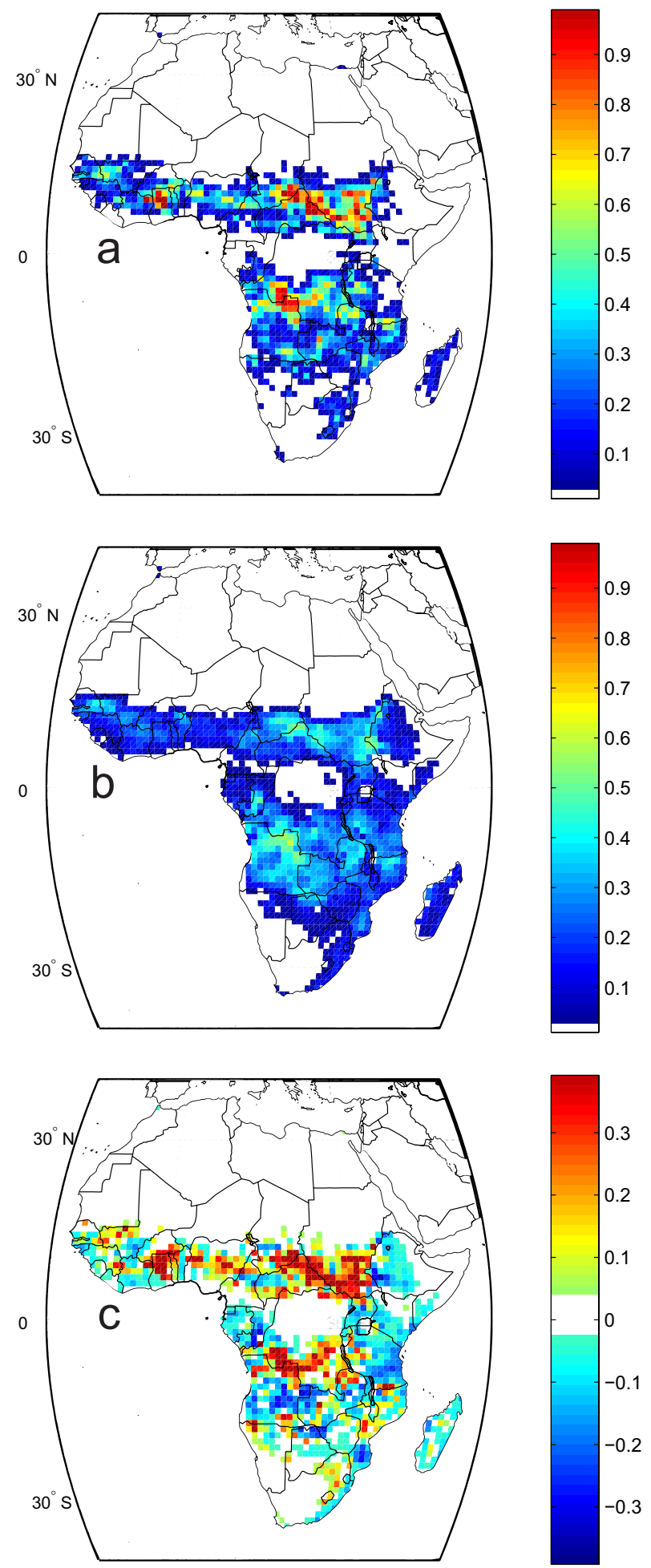

Fig. 4. Fraction of area burned in the fire year 2007. Panel (a) remotely sensed from MODIS MCD45; panel (b) predicted from the parameterised fire model VC. Panel (c) residuals observed predicted from model VC. Data for the year 2007 is not used for the estimation of the model parameters (Table 1).
The model has one parameter for the linear part $l_{1}$ to $l_{7}$ for each variable $v_{1}$ to $v_{7}$, and another one ( $s_{1}$ to $\left.s_{7}\right)$ for the squared part. All parameters of model $\mathrm{VC}$ are listed in Table 1. The final model VC also includes a constant term (a) with a value of -10.6 (Table 1). For comparison, the parameter- and R-values of model $\mathrm{C}$ are listed in Table A1 in the Appendix. The predicted and observed burned area as well as the residuals for the "fire year" 2007 are shown in Fig. 4 for model VC and Fig. A1 in the Appendix for model C.

Model VC performs well in predicting the geospatial burned area pattern, with absence of notable burned area in very dry areas like the Sahara or Kalahari desert and in wet areas like the tropical rain forest. It captures the geographic distribution of fires across the savannah biome well, but it does not pick up regions with high burned area fractions above 0.5. Overall the predicted burned area shows a lower spatial variability compared to the remotely sensed burned area. Model $\mathrm{C}$ has a much lower performance not only in the total agreement reached (R-value), but also in the representation of the spatial pattern (Appendix, Fig. A1).

\subsection{Inter-annual variability}

We also investigated the inter-annual variability, in this case using the estimated parameters to predict not only the evaluation dataset but the full dataset. The predicted burned area fractions were then used to examine inter-annual variation using the standard deviation (of the average burned area fraction) for each grid cell between years. The spatial distribution of the inter-annual variability of burned area as detected by MODIS and predicted by model VC is shown in Fig. 5 (model C Fig. A1, Appendix). Though areas experiencing a high inter-annual variability are correctly depicted, the total amount of the inter-annual variability is underestimated by model VC.

\subsection{Intra-annual variability}

The two Hovmöller diagrams in Fig. 6 illustrate the intraannual distribution of the remotely sensed wildfires, and the Nesterov index derived from the climate data, respectively. The highest fire activity in the Northern Hemisphere is detected between October and February and in the southern part the majority of wildfires occur between May and October. In both hemispheres the burn seasons shift to later periods from north to south. The fire season in the northern part is shorter and more pronounced than in the Southern Hemisphere where the burning especially south of $10^{\circ} \mathrm{S}$ occurs over a longer time-span at a low level.

The Nesterov index, the cumulative index of the dryness is limited, according to our definition, to a maximum of $2 \times 10^{5}$, values that were reached only in the Saharan desert. Figure $6 \mathrm{~b}$ indicates that the timing of the dry season depends strongly on latitude. In the part of the Northern Hemisphere 

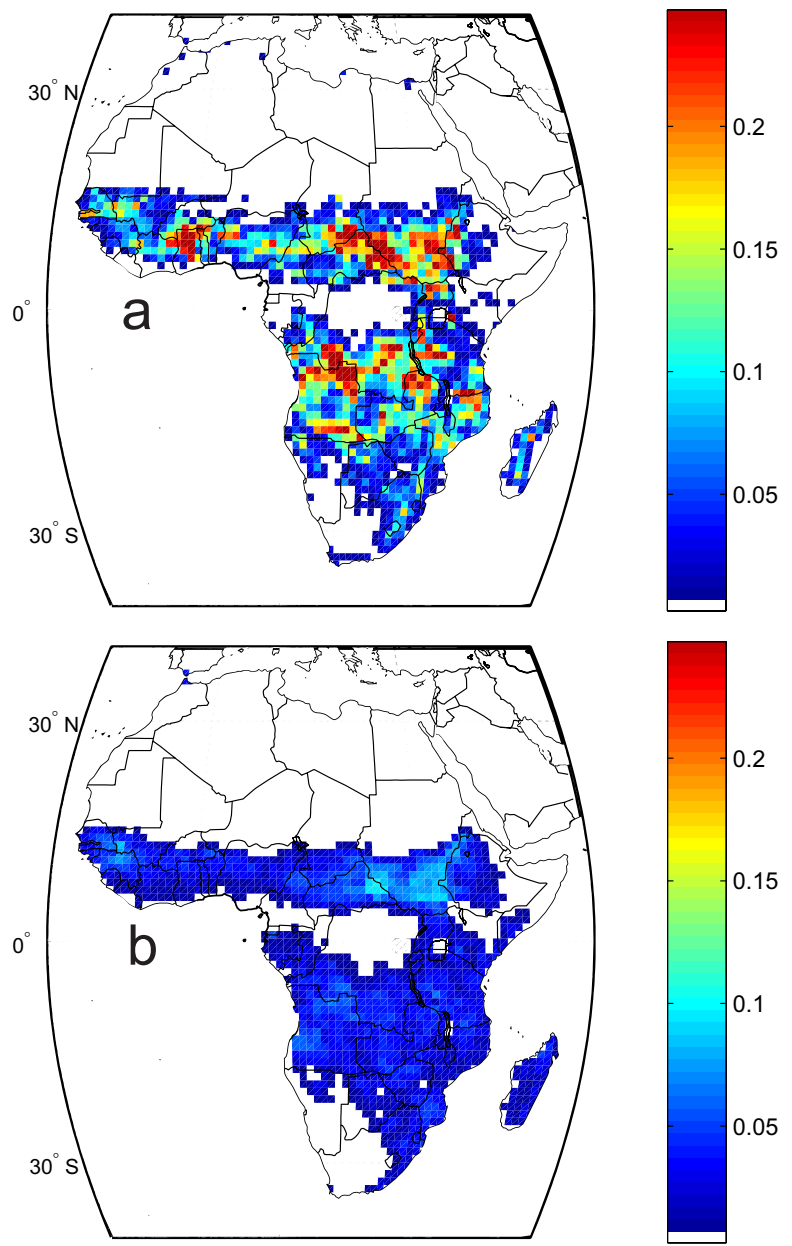

Fig. 5. Standard deviation of fraction of burned area from 2000 to 2008. Panel (a) directly derived from MODIS burned area product MCD45; panel (b) predicted from model VC, using all available years.

where the majority of fires occur, the dry season starts in September and lasts until May, while in the latitudinal band where wildfires occur in the Southern Hemisphere it lasts from May until September. Visual comparison of the two diagrams in Fig. 6 shows that in both hemispheres the majority of fires are found during the first half of the dry season.

In order to find a quantitative relation between the burned area and the Nesterov index, we binned the values of the logarithms of the index $\left(N_{i}\right)$ and added all the burned area fractions, for each bin. After scaling the values to a total area of unity we fitted a lognormal distribution (Fig. 7; Eq. 6). The result can be interpreted as a probability density for the fire activity. The maximum is found at a Nesterov index of ca. $10^{4}$, more precisely the parameter $\mu$ of the fitted lognormal distribution equals to 3.95 and the parameter $\sigma$ to 0.495 . The relative fraction of burned area $b_{\mathrm{a}_{\mathrm{r}}}$ can hence be estimated for each day using Eq. (6).
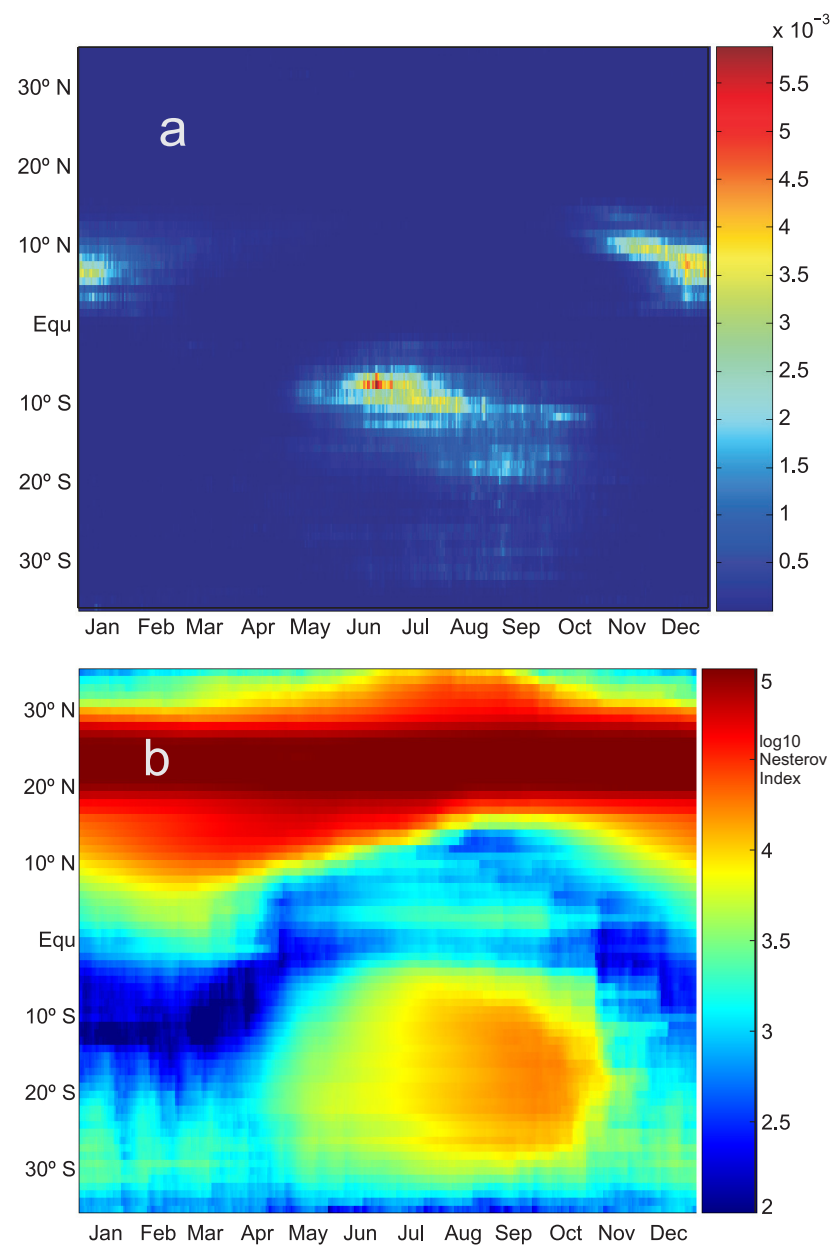

Fig. 6. Hovmöller diagram of remotely sensed daily ratio of burned area per day (a) and of daily latitudinal averages of the Nesterov index based on the climate data, averaged over the period from 20002008 (b). The red areas between $20^{\circ} \mathrm{N}$ and $30^{\circ} \mathrm{N}$ in panel (b) are for the Saharan desert where the Nesterov index was never reset to zero (requires rain event $>3 \mathrm{~mm}$ per day) during the study period.

$b_{\mathrm{a}_{\mathrm{r}}}=\frac{1}{\sqrt{2 \pi \sigma^{2}}} \exp \frac{-\left(\log _{10} N_{i}-\mu\right)^{2}}{2 \sigma}$

To check the resulting relationship between the burned area fraction and the Nesterov index we used the test area between $20^{\circ} \mathrm{E}$ and $30^{\circ} \mathrm{E}$ (Fig. 1) and correlated the calculated sums of burned area fractions estimated from Eq. (6) with the observed ones, resulting in an R-value of $0.89(p<0.001)$. The relationship in Eq. (6) can be used to add intra-annual time dependence to our model. This is shown for an example grid cell in Fig. 8. Panel (a) displays the Nesterov index over the year 2007. We then distribute the relative fraction burned over the year, based on the seasonality of $N_{i}$ using Eq. (6). Finally we scale the prediction of the fraction burned given by our model (Eq. 5) so that the total sum of the relative fractions (Eq. 6) equals the burned area estimated from Eq. (5) and obtain panel (c). A comparison with the 


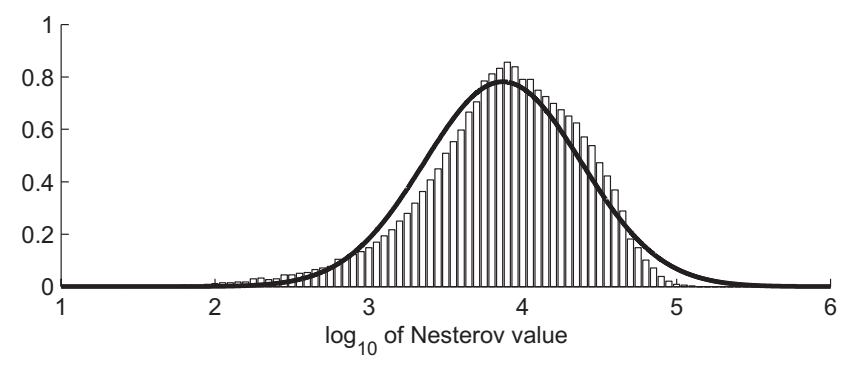

Fig. 7. Sum of burned area fractions versus $\log _{10}$ of the Nesterov indices, rescaled to a maximum area of 1 . This curve was generated using the same training data as used in the remaining analysis (e.g. all locations outside the area from $20^{\circ} \mathrm{E}$ to $30^{\circ} \mathrm{E}$ indicated in Fig. 1).
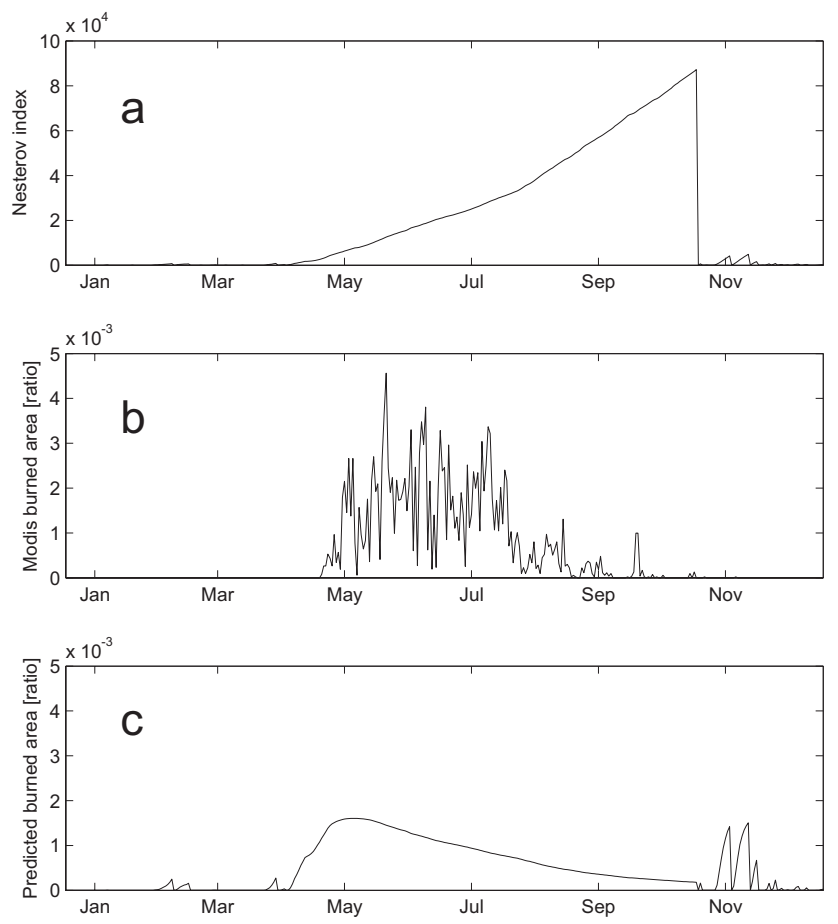

Fig. 8. Intra-annual wildfire activity. Temporal distribution of the Nesterov index (a), the observed burned area (b) and the predicted temporal distribution of ratio burned (c) for an example gridcell $\left(-12^{\circ} \mathrm{S}\right.$ and $\left.27^{\circ} \mathrm{E}\right)$ in the year 2007.

observed daily burned area distribution (Fig. 8b) shows the agreement between the timing of the observed and predicted burned area, with a smoother seasonal course in the statistical model than observed by the satellite. The predicted burned area (Fig. 8c) shows two peaks in November while MODIS senses no fire activities around that time. This is caused by the fact that our prediction of the timing of the fire activities depends solely on the Nesterov index. If a short dry period within the wet season causes the Nesterov index to reach values indicating a fire potential, it predicts a fire activity re-
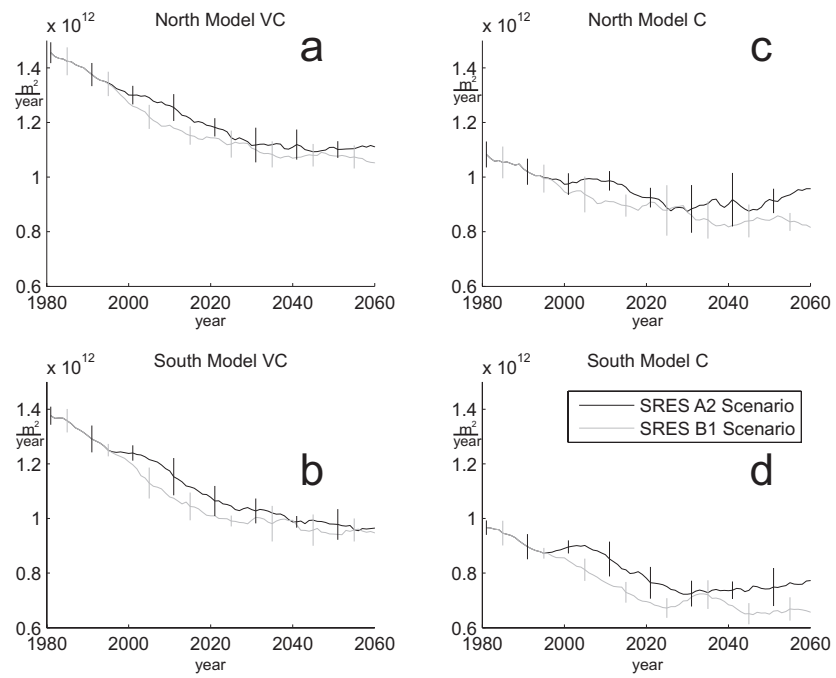

Fig. 9. Projected burned area of the Northern (a and c) and Southern (b and d) Hemisphere of Africa using model VC (a and b) and model $\mathrm{C}$ ( $\mathrm{c}$ and $\mathrm{d}$ ) for the two SRES storylines A2 and B1 from 1980-2060. The time period from 1980-2000 is derived from the control simulation of the 20th century. Lines are 10-year moving averages and bars show the standard deviation within the 10 years.

gardless of the time of the year. However, since these periods are relatively short, the total error in terms of the intra-annual fire distribution is rather small.

\subsection{Model application - simulated burned area}

Applying the two burned area models to projected climate and population data results in the total burned areas as displayed in Fig. 9. At continental scale, all considered climate variables show relatively small changes over the simulation period (Fig. 2). While the total precipitation is similar in the two climate simulations, the Nesterov index as well as the total population reaches higher values in the A2 scenario. However, the displayed hemispheric totals include not only the savannah regions (since their spread might change over time) but also the tropical rain forest and the large deserts, hence local differences in the savannah regions are not reflected well in Fig. 2.

The simulated burned area for the time period from 1980 to 2060 decreases over time in both hemispheres and for both scenario projections (Fig. 9). The variability of model VC (Fig. 9a, b) is smaller than the variability of model C (Fig. 9c, d) which takes only the climate variables into account. The decline in $b_{\mathrm{a}}$ calculated with model VC lies at ca. $0.3 \times 10^{12} \mathrm{~km}^{2}$ (ca. $20-25 \%$ of the maximum value at the beginning of the simulation) in both hemispheres, though the total values are lower in the Southern Hemisphere (Fig. 9a, b). Model $\mathrm{C}$ estimates lower burned areas at the beginning of the experiment, a smaller decline as well as a larger interannual variability. The simulation based on the SRES A2 storyline results in higher burned areas but the differences 

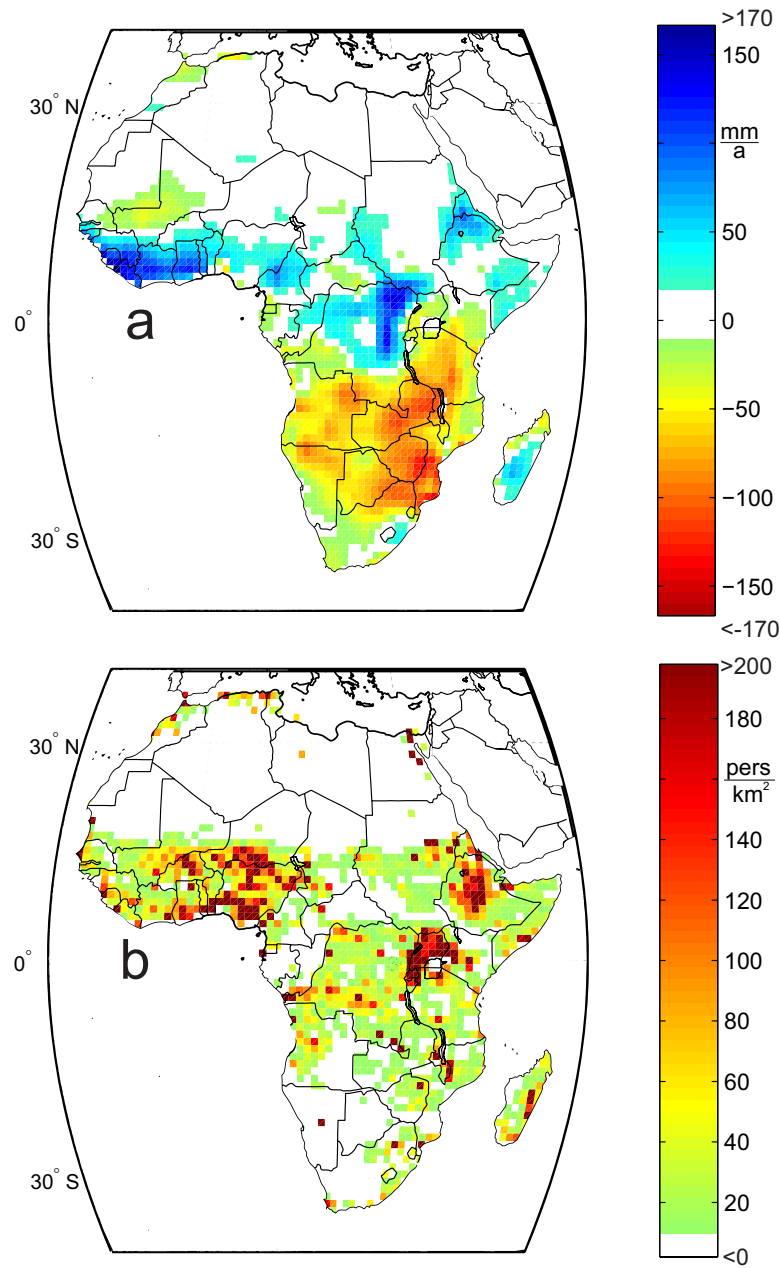

Fig. 10. Projected changes in mean annual precipitation (a) and population density (b) for the SRES storyline B1 and the ECHAM climate model (see methods section). Panels are plotted as the difference between the average of the years 2050 to 2060 and 1990 to 2000.

are not significant, since the standard deviations of the total burned areas of both scenarios overlap in the majority of cases.

The projected spatial distribution of the changes in rainfall pattern over Africa shows a strong dipole pattern (Fig. 10a) Large parts of the Southern Hemisphere that coincide with areas of high wildfire activity under present-day conditions (Fig. 1) are expected to experience a decline in MAP of up to $150 \mathrm{~mm}$, whereas in other areas precipitation is expected to increase by approximately the same amount - hence the relatively conservative totals seen in Fig. 2. By contrast to the hemispheric differences in precipitation, the population is expected to increase across the whole continent (Fig. 10b), with highest population growth projected for the northern parts. Figure 10 illustrates responses from the B1 scenario, but the observed patterns in the A2 scenario were not qualitatively different (not shown).
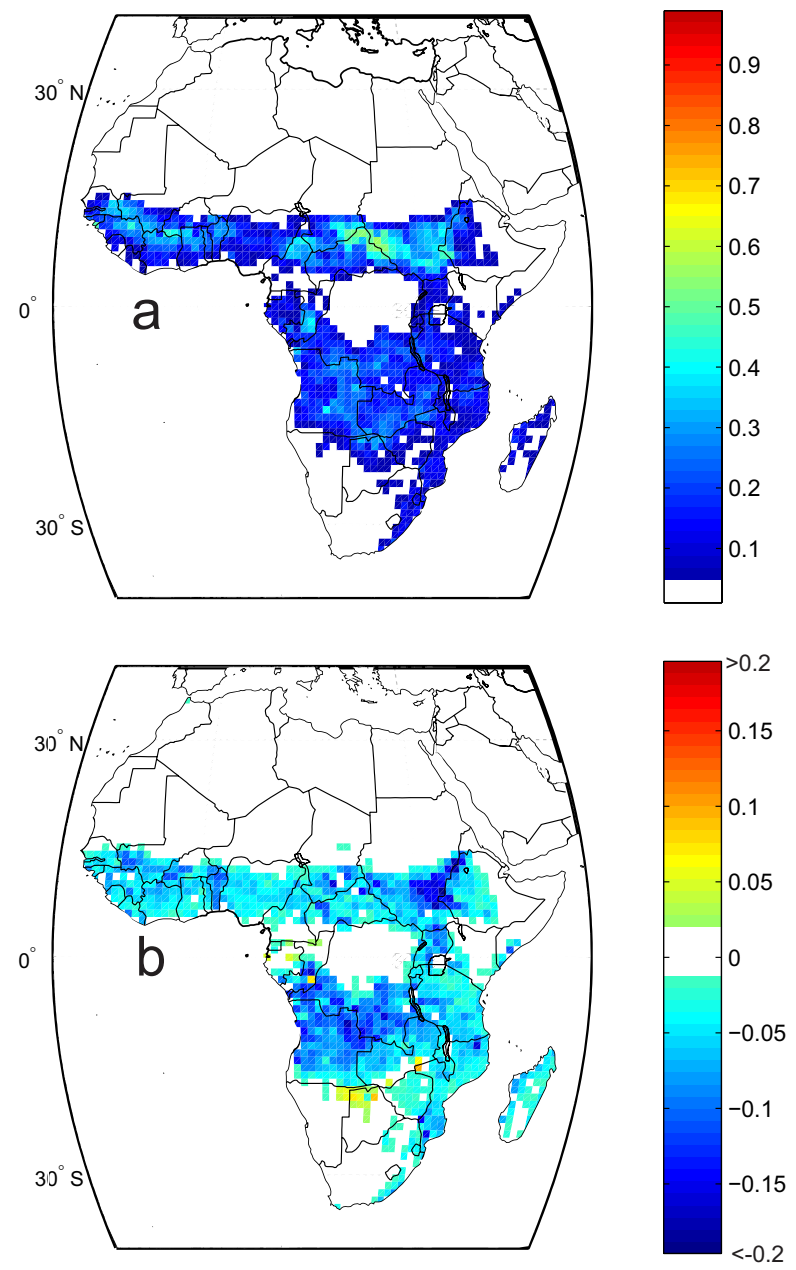

Fig. 11. Projected burned area fraction across Africa calculated from model VC according to the climate and population development relating to SRES storyline B1. Displayed are the average burned fraction from 2050 to 2060 (a) and the average of the years 2050 to 2060 minus the average of the years 1990 to 2000 (b).

Projections for the period 2050 to 2060 show the strongest decrease in fraction of area burned in areas which currently experience the highest wildfire activity (Fig. 11a, b; Fig. 1) but simulated variability between gridcells remains low, a similar to pattern to that observed with the statistical model for present-day conditions (see Fig. 4). While in the Northern Hemisphere, the areas experiencing high fire activities are also still in the projection experiencing a higher fire activity than surrounding areas, in the southern part of the hemisphere this is not the case. The simulations indicate that based on the variables considered in the GLM the decline in burned area is not associated with a decline in specific regions, but rather a relatively uniform response across the savannah biome. 


\section{Discussion}

The correct simulation and prediction of continental or global wildfire pattern is, despite of being interesting in itself, a crucial part in the predictive modelling of vegetation distribution, structure, and the exchanges of greenhouse gases and pyrogenic substances.

\subsection{Burned area model variables and resolution}

The presented statistical analysis has been designed especially for its suitability to be incorporated in DVMs or ESMs, noting that the necessary choice of a sub-set of applicable variables might lead to a lower performance compared to other approaches that are not restricted in the choice of the explanatory data (e.g. Archibald et al., 2009). However, the selected variables precipitation, Nesterov index (reflecting potential fuel dryness and being related to precipitation), tree and herb cover, and population density are key determinants of fire patterns (Archibald et al., 2009) and are available for historic and projected time periods and commonly simulated by DVMs. Model VC represented the spatial distribution of area burnt reasonably well, but the inter-annual variability and maximum burn fraction were underestimated. One likely reason for the underestimation of temporal and spatial variability is the broad geographic scale at which the analysis was performed. Both, individual fires as well as precipitation vary substantially on a scale much below the one degree spatial resolution of this analysis. Moreover, additional variables influence the annual burned area but are not considered here, like landscape fragmentation (density of roads), land use practices, differences in the developmental stage of the agricultural systems and the fire suppression policy (e.g. Archibald et al., 2009). Simulation of land use pattern is not common in DVMs yet (Arneth et al., 2010b) and while a spatially explicit projection of changes in land use is available for the 21th century for Europe (Reginster and Rounsevell, 2006), nothing comparable is available for the African continent to the knowledge of the authors.

Additionally, the variable "tree cover" which had the highest explanatory value was only available as a static dataset for the year 2001. This is problematic for the development of the statistic model since fire can potentially have strong impacts on tree and herb cover over time and therefore change their relative distribution on an inter-annual basis (Arneth et al., 2010a). Therefore we consider the agreement between the final model and the data reasonable, keeping in mind also the uncertainties in the burned area data (see Methods section) and noting the limitations introduced by the high level of aggregation due to the required one degree scale.

The analysis demonstrated that the vegetation and productivity related variables i.e. tree and herb cover as well as precipitation over the last 4 seasons and over the preceding wet season were ranked above variables relating to the dryness of the fuel i.e. precipitation over the dry season and Nesterov index (Table 1). This indicates that in the majority of cases the fuel load is by far more important to estimate the area burnt fraction than the dryness, since the dry season in most parts of African savannas are sufficiently long to generate fire prone conditions. The strongly enhanced predictive power of the GLM when including vegetation-derived variables calls for development of improved remote sensing products of vegetation structural properties with at least annual resolution. It moreover also indicates how future projections of fire regimes cannot be performed without robust simulations of the dynamic growth response of vegetation to interacting climate and atmospheric $\mathrm{CO}_{2}$ concentration.

\subsection{Additional drivers of wildfires and spatial resolution}

An earlier fire model for the application in global models was developed by Pechony et al. (2009), using similar driving variables and additionally accounting for lightning as a driver. Though lightning is assumed to be the only natural ignition source potentially resulting in a considerable amount of wildfires, we decided not to include this variable here because natural ignitions are likely of minor importance in Africa, at least under the present-day fire regime (Saarnak, 2001). Additionally, the spatial resolution of the remotely sensed lightning data (e.g. $2.5^{\circ}$, Christian et al., 1996) and the data quality of the available daily resolution products is not sufficient to robustly estimate natural ignitions. A previous attempt to use these data showed that it is problematic to separate between lighting strikes occurring before the rain event and strikes which occur during a rain event, the latter imposing a very low risk of fire ignition (Arneth et al., 2010a). Ignition caused by lighting is prone to be overestimated using the currently available global datasets. Still, for model applications that seek to study changes in fire regimes into the past or into the future a separate treatment of lightning is desirable because the paleo-record of fire puts forward strong arguments for a mostly climate-driven fire regime (Marlon et al., 2008), and since climate change is expected to change patterns of thunderstorms and lightning (Price and Asfur, 2006). Even though fires are in most cases ignited by humans for a variety of purposes (land management, hunting, agriculture practices; Saarnak, 2001) our study shows that climate variables are still more important factors in explaining fire occurrence than population density.

Our results are in agreement with the findings of Archibald et al. (2009) who also ranked the importance of population density below all climate and vegetation related drivers of burned area (though still at position five out of 11 investigated drivers). Their study, which was conducted at a comparable resolution to ours found no evidence that ignition frequency either limited or promoted the burnt area, since ignition does not succeed to a spreading fire succeed without otherwise favourable environmental conditions. High population densities however are linked to low fire frequencies 
due to fire prevention, extinction and low fuel loads. At the spatial resolution of our analysis we can hardly represent the effects of an uneven population distribution occurring within a grid cell. The grid cells can vary in size from $1.2 \times 10^{4} \mathrm{~km}^{2}$ at the equator to $1.0 \times 10^{4} \mathrm{~km}^{2}$ at the most northern part of Africa, even though a high population density might be assigned to a certain cell, parts of the cell can still be less densely populated and hence subject to wildfires. Thus the detected correlation, and probably also the spatial variability would likely increase substantially if the necessary information was available on a finer resolution.

\subsection{Evaluation of model performance}

Our assessment of model performance was based on the Rvalue and the BIC. Relying solely on R-values might be problematic in cases of nonlinear relationships, and can potentially lead to over-fitting by ignoring the number of parameters used for the analysis. By contrast, the BIC applies a weight to the number of variables to select the best model (Schwarz, 1978). All factors considered in our regression model represent certain aspects of the conditions that determine the overall burned area, and the BIC statistics did not provide a strong argument to discard any of these although their relative importance will vary. In addition to causal correlation a considerable amount of spatial auto-correlation is present in the explanatory as well as in the predicted variables. We separated the available datasets into groups and tested the model performance only on data not used to estimate the fire model parameters. But since our model focuses on the continental wildfire patterns for large-scale applications rather than analyzing causal relationships per se, a more complete analysis of the influence of the spatial autocorrelation on the variables is beyond the scope of this work. Our listing of the driving variables thus also does not consider a ranking or effects including variables in different order.

Aiming to pool all available data in a valid way, we used a "fire year" instead of the Julian year and shifted the seasons between northern and southern Africa. However, a parameterization for a global model (e.g. Pechony and Shindell, 2009) requires a distinction between different regions, like presented by Giglio et al. (2006) to reflect existing variation between larger regions in their fire regime and/or the variable use of fire as a land management tool. It is to be expected, for instance, that a parameterisation for mean precipitation of the last four seasons, which was shown to have a strong influence on the African fires would not work in boreal forests. For Africa, precipitation is the main driver of productivity and hence available litter to burn, while in cooler environments, accumulated temperature becomes an additional important factor (Crevoisier et al., 2007).

\subsection{Temporal distribution of burned area fractions}

To the knowledge of the authors, this study is the first to propose a statistical procedure to distribute fire events over the course of the year. The correct timing of fire events is important since the effects of fires on vegetation and on the atmospheric composition strongly depend on fire intensity and hence on the climatic conditions. We related timing of fires to the fuel dryness represented by the Nesterov index. The derived uni-modal relationship with a peak at a medium $N_{i}$ (Fig. 7) value indicates that the time of human fire ignitions is chosen to be mostly in the first half of the dry season which has also been stated by Saarnak (2001). For a natural (lightning-driven) fire regime we expect a shift towards relatively larger fraction of burned area to coincide with high Nesterov index values, since most lightning strikes would occur just before the wet season (dry lightning). Though rare in numbers, dry lightning could potentially burn large areas that would have had a high fuel accumulation in the absence of a human driven fire regime. Over the course of the year, the Nesterov index (see Fig. 6b) decreased less abruptly than shown in Fig. 8a, mainly because of latitudinal and interannual averaging. Distributing the burned area temporally based on such smooth seasonal transitions could potentially lead to an incorrectly simulated second fire season at the end of the dry season. However, within a single cell, the Nesterov index drops from the maximum level to zero at the first day with $3 \mathrm{~mm}$ or more precipitation (Fig. 8a). Within a dynamic vegetation model, the daily fraction of burned area can hence directly be calculated from Nesterov index using Eqs. (5) and (6) due to the sharp decline within the single cell (Fig. 8a) compared to the latitudinal average (Fig. 6b).

\subsection{Burned area projection}

The simulated burned areas for the year 1997 to 2008 of model VC are comparable to values estimated by Giglio et al. (2010) who estimated burned area to lie between $1.1 \times 10^{12} \mathrm{~m}^{2}$ and $1.5 \times 10^{12} \mathrm{~m}^{2}$ for these years, with a mean of $1.31 \times 10^{12} \mathrm{~m}^{2}$ for the Northern Hemisphere. For Southern Hemisphere regions the authors found a similar range, but a slightly smaller mean compared to our estimates of $1.25 \times 10^{12} \mathrm{~m}^{2}$ for the Southern Hemisphere of Africa. This encourages the use of the simulated climate data in connection with the parameterized model I since the climate data used here is (though for an overlapping time period) an independent simulation of the climate variables from the GCM which also generated the future projection of the climate.

The application of the two parameterised GLMs using simulated climate data for the period from 1980 to 2060 resulted in a considerable decrease of burned area regardless of the scenario and model applied (Fig. 9). Both the strong decline, as well as the similarity in trends between the two hemispheres is at first surprising. Continental precipitation sums (2-year mean, dry and wet season precipitation 
Fig. 2) show no obvious trend over time, but the spatial pattern shows a general decrease in MAP especially in the Southern Hemisphere, but an increase mainly in the Northern Hemisphere regions. This is in agreement with the IPCC 4th Assessment report which states that during recent decades, eastern Africa has been experiencing an intensifying dipole rainfall pattern with increasing rainfall over the northern sector and decreased rainfall over the southern sector (Schreck and Semazzi, 2004; Boko et al., 2007). According to the parameterized model VC, decreasing MAP should lead to a reduced burned area in those regions with a MAP not higher than $1100 \mathrm{~mm}$ before the decrease, mostly because of the associated effects on reduced productivity and litter input. Therefore, the decreasing trend simulated for the Southern Hemisphere regions are likely driven by changes in MAP, enhanced by increasing population density. For the Northern Hemisphere regions, the projected population increase more than compensates effects of increased precipitation in our model.

Fire has been applied as a land management tool in Africa over millennia. A decreasing trend at least for the Northern Hemisphere was seen in the remotely sensed burned areas estimated by Giglio et al. (2010), and our future simulations project a continuing, considerable decrease regardless of the experiment and scenario. The vast majority (ca. 90\%) of the Africa's population depends on rain-fed crop production and pastoralism within the savannah biome to meet its basic food supplies (Patt and Winkler, 2007). Therefore, if burned area would be interpreted as an indictor for the total area suitable for a variety of human activities to produce food, the calculated reduction should be of major concern for inhabitants in these regions.

\section{Conclusions}

Understanding fire driving factors is fundamentally important for developing process-based simulation models of fire occurrence under future climate and environmental change scenarios. This study offers a tool to estimate burned area for a variety of purposes. It provides both, the estimation of the total burned area as well as the intra-annual distribution of the fire activity over the year. The application of the models to climate change projections shows the potential of the derived model and the strong decrease in burned area, which is related to favourable conditions for food production, demonstrates the impact that the expected climatic changes will have for Africa.
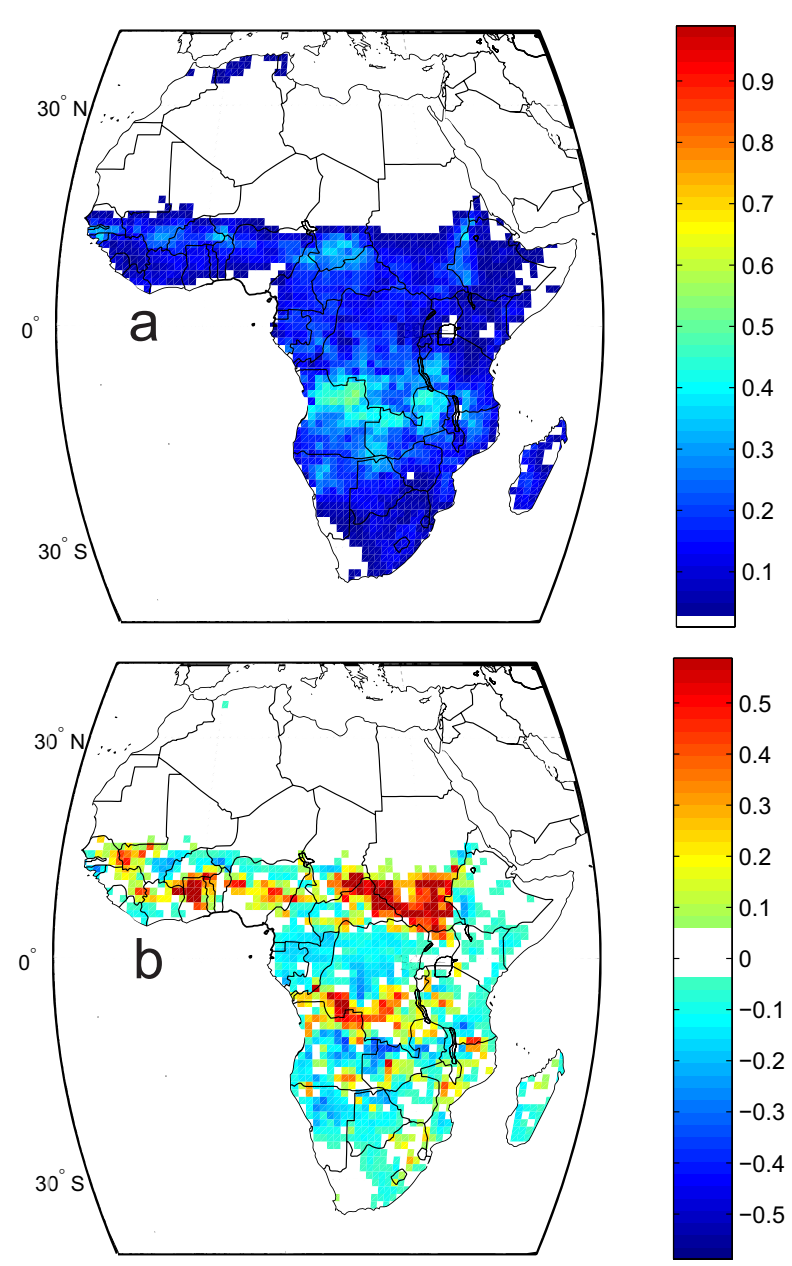

Fig. A1. Fraction of area burned in the fire year 2007. Panel (a) predicted from the parameterised fire model C. Panel (b) residuals observed (remotely sensed from MODIS MCD45; see Fig. 4a) predicted from model C. Data for the year 2007 is not used for the estimation of the model parameter (Table A1).

\section{Appendix A}

\section{Parameter and performance of model C (Burned area model with reduced variable set)}

The general form of model $\mathrm{C}$ is similar to the form of model VC conforming to Eq. (A1). Instead of seven, the reduced set has only five parameters, as listed in Table A1. The predicted ratios of area burned are given in Fig. A1. Similar to model $\mathrm{VC}$, we used the natural logarithm instead of the actual value for the variables dry season precipitation and population density.

$$
b_{\mathrm{a}}=\frac{1}{1+e^{-\left(a+\sum_{i=1}^{5} l_{i} v_{i}+s_{i} v_{i}^{2}\right)}}
$$

For further information refer to the explanation given for Eq. (5). 
Table A1. Parameterisation of model C. Correlation coefficient (Rvalue) of all single variable models and linear and squared coefficients for model $\mathrm{C}$. The constant term for the final model is -7.91 . The abbreviations $v, l$ and $s$ are used in Eq. (A1).

\begin{tabular}{llll}
\hline Model variables $(v)$ & $\begin{array}{l}\text { Corr. coeff. } \\
\text { sing. var. } \\
\text { model }\end{array}$ & $\begin{array}{l}\text { Linear coeff. } \\
\text { in final } \\
\text { model }(l)\end{array}$ & $\begin{array}{l}\text { Squared coeff. } \\
\text { in final } \\
\text { model }(s)\end{array}$ \\
\hline $\begin{array}{l}\text { Mean Precipitation } \\
\text { last } 4 \text { seas. [mm] }\end{array}$ & 0.49 & $8.66 \times 10^{-3}$ & $-3.62 \times 10^{-6}$ \\
$\begin{array}{l}\text { Precipitation } \\
\text { Rain-season [mm] }\end{array}$ & 0.46 & $9.68 \times 10^{-4}$ & $-3.07 \times 10^{-7}$ \\
$\begin{array}{l}\text { Nesterov maximum } \\
\text { [see above] }\end{array}$ & 0.39 & $3.80 \times 10^{-5}$ & $-1.93 \times 10^{-10}$ \\
$\begin{array}{l}\text { log(Population } \\
\left.\left.\text { density [per/km }{ }^{2}\right]\right)\end{array}$ & 0.27 & $-5.72 \times 10^{-2}$ & $-2.29 \times 10^{-1}$ \\
$\begin{array}{l}\log (\text { Precipitation } \\
\text { Dry-season }[\mathrm{mm}])\end{array}$ & 0.26 & $3.91 \times 10^{-1}$ & $-4.95 \times 10^{-2}$ \\
\hline
\end{tabular}

Acknowledgements. This study was funded by the European Commission by the 6th FP project CarboAfrica. The comments of Sally Archibald on an early version of this manuscript are acknowledged.

Edited by: F. X. Meixner

\section{References}

Archibald, S., Roy, D. P., van Wilgen, B. W., and Scholes, R. J.: What limits fire? An examination of drivers of burnt area in Southern Africa, Glob. Change Biol., 15, 613-630, 10.1111/j.1365-2486.2008.01754.x, 2009.

Arneth, A., Lehsten, V., Spessa, A., and Thonicke, K.: Climatefire interactions and savanna ecosystems: a dynamic vegetation modelling study for the African continent, in: Ecosystem Function in Savannas: Measurement and Modeling at Landscape to Global Scales, edited by: Hill, M. J. and Hanan, N. P., CRC Press, 2010a.

Arneth, A., Sitch, S., Bondeau, A., Butterbach-Bahl, K., Foster, P., Gedney, N., de Noblet-Ducoudré, N., Prentice, I. C., Sanderson, M., Thonicke, K., Wania, R., and Zaehle, S.: From biota to chemistry and climate: towards a comprehensive description of trace gas exchange between the biosphere and atmosphere, Biogeosciences, 7, 121-149, doi:10.5194/bg-7-121-2010, $2010 \mathrm{~b}$.

Bengtsson, M., Shen, Y. J., and Oki, T.: A SRES-based gridded global populatiou dataset for 1990-2100, Population and Environment, 28, 113-131, doi:10.1007/s11111-007-0035-8, 2006.

Bird, M. I. and Cali, J. A.: A million-year record of fire in subSaharan Africa, Nature, 394, 767-769, 1998.

Boko, M., Niang, I., Nyong, A., Vogel, C., Githeko, A., Medany, M., Osman-Elasha, B., Tabo, R., and Yanda, P.: Africa, in: Climate Change 2007: Impacts, Adaptation and Vulnerability, Contribution of Working Group II to the Fourth Assessment Report of the Intergovernmental Panel on Climate Change, edited by: Parry, M. L., Canziani, O. F., Palutikof, J. P., van der Linden, P. J., and Hanson, C. E., Cambridge University Press, Cambridge UK, 433-467, 2007.
Christian, H. J., Driscoll, K. T., Goodman, S. J., Blakeslee, R. J., Mach, D. A., and Buechler, D. E.: The Optical Transient Detector (OTD), 10th International Conference on Atmospheric Electricity, Osaka, Japan, 1996.

Crevoisier, C., Shevliakova, E., Gloor, M., Wirth, C., and Pacala, S.: Drivers of fire in the boreal forests: Data constrained design of a prognostic model of burned area for use in dynamic global vegetation models, J. Geophys. Res., 112, D24112, doi:10.1029/2006JD008372, 2007.

Foken, T.: Angewandte Meteorologie, 2nd Edn. 1996, Springer Verlag, Berlin, p. 43, 2003.

Giglio, L., van der Werf, G. R., Randerson, J. T., Collatz, G. J., and Kasibhatla, P.: Global estimation of burned area using MODIS active fire observations, Atmos. Chem. Phys., 6, 957974, doi:10.5194/acp-6-957-2006, 2006.

Giglio, L., Randerson, J. T., van der Werf, G. R., Kasibhatla, P. S., Collatz, G. J., Morton, D. C., and DeFries, R. S.: Assessing variability and long-term trends in burned area by merging multiple satellite fire products, Biogeosciences, 7, 1171-1186, doi:10.5194/bg-7-1171-2010, 2010.

Hansen, M. C., DeFries, R. S., Townshend, J. R. G., Carroll, M., Dimiceli, C., and Sohlberg, R. A.: Global Percent Tree Cover at a Spatial Resolution of 500 Meters: First Results of the MODIS Vegetation Continuous Fields Algorithm, Earth Interact., 7(10), 1-15, 2003.

Harris, S., Tapper, N., Packham, D., Orlove, B., and Nicholls, N.: The relationship between the monsoonal summer rain and dryseason fire activity of northern Australia, Int. J. Wildland Fire, 17, 674-684, doi:10.1071/wf06160, 2008.

Healy, E.: Population density in: FAO-UN; available at: http: //www.fao.org/geonetwork/, 2008.

Hough, J. L.: Why burn the bush?, Social approaches to bush-fire management in West African National parks, Biol. Conserv., 65, 23-28., 1993.

Kummerow, C., Barnes, W., Kozu, T., Shiue, J., and Simpson, J.: The Tropical Rainfall Measuring Mission (TRMM) sensor package, J. Atmos. Ocean. Tech., 15, 809-817, 1998.

Lehsten, V., Tansey, K., Balzter, H., Thonicke, K., Spessa, A., Weber, U., Smith, B., and Arneth, A.: Estimating carbon emissions from African wildfires, Biogeosciences, 6, 349-360, doi:10.5194/bg-6-349-2009, 2009.

Marlon, J. R., Bartlein, P. J., Carcaillet, C., Gavin, D. G., Harrison, S. P., Higuera, P. E., Joos, F., Power, M. J., and Prentice, I. C.: Climate and human influences on global biomass burning over the past two millennia, Nat. Geosci., 1, 697-702, 2008.

Mbow, C., Goita, K., and Benie, G. B.: Spectral indices and fire behavior simulation for fire risk assessment in savanna ecosystems, Remote Sens. Environ., 91, 1-13, doi:10.1016/j.rse.200310.019, 2004.

Mbow, C., Nielsen, T. T., and Rasmussen, K.: Savanna Fires in East-Central Senegal: Distribution Patterns, Resource Management and Perceptions, Hum. Ecol. Spec. Issue, 28, 561-583, 2000.

Nesterov, V. G.: Gorimost' lesa i metody eio opredelenia., Goslesbumaga, 1-75, 1949.

Patt, A. G. and Winkler, J.: Applying climate information in Africa: an assessment of current knowledge, Boston University, 19-37, 2007. 
Pechony, O. and Shindell, D. T.: Fire parameterization on a global scale, J. Geophys. Res., 114, D16115, doi:10.1029/2009JD011927, 2009.

Price, C. and Asfur, M.: Inferred long term trends in lightning activity over Africa, Earth Planets Space, 58, 1197-1201, 2006.

Reginster, I. and Rounsevell, M.: Scenarios of future urban land use in Europe, Environ. Plann. B, 33, 619-636, 2006.

Roeckner, blackboxInitial?: IPCC MPI-ECHAM5_T63L31 MPIOM_GR1.5L40 20C3M_all run no. 1: atmosphere 6 HOUR values, in: MPImet/MaD Germany, World Data Center for Climate, 2005.

Roy, D. P., Boschetti, L., Justice, C. O., and Ju, J.: The Collection 5 MODIS Burned Area Product - Global Evaluation by Comparison with the MODIS Active Fire Product, Remote Sens. Environ., 112, 3690-3707, 2008.

Roy, D. P. and Boschetti, L.: Southern Africa Validation of the MODIS, L3JRC, and GlobCarbon BurnedArea Products, IEEE T. Geosci. Remote, 47, 1032-1044, doi:10.1109/tgrs.2008.2009000, 2009.

Roy, P. D., Ju, J., Mbow, C., Frost, P., and Loveland, T.: Accessing free Landsat data via the Internet: Africa's challenge, Remote Sensing Letters, 1, 111-117, 2010.

Saarnak, C. F.: A shift from natural to human-driven fire regime: implications for trace-gas emissions, Holocene, 11, 373-375, 2001.

Schreck, C. J. and Semazzi, F. H. M.: Variability of the recent climate of eastern Africa, Int. J. Climatol., 24, 681-701, 2004.

Schwarz, G.: Estimating the Dimension of a Model, Ann. Stat., 6, 461-464, 1978.
Smith, B., Prentice, I. C., and Sykes, M. T.: Representation of vegetation dynamics in the modelling of terrestrial ecosystems: comparing two contrasting approaches within European climate space, Global Ecol. Biogeogr., 10, 621-637, 2001.

Spessa, A., McBeth, B., and Prentice, C.: Relationships among fire frequency, rainfall and vegetation patterns in the wet-dry tropics of northern Australia: an analysis based on NOAA-AVHRR data, Global Ecol. Biogeogr., 14, 439-454, 2005.

Thonicke, K., Spessa, A., Prentice, I. C., Harrison, S. P., Dong, L., and Carmona-Moreno, C.: The influence of vegetation, fire spread and fire behaviour on biomass burning and trace gas emissions: results from a process-based model, Biogeosciences, 7, 1991-2011, doi:10.5194/bg-7-1991-2010, 2010.

van der Werf, G. R., Randerson, J. T., Giglio, L., Collatz, G. J., Kasibhatla, P. S., and Arellano Jr., A. F.: Interannual variability in global biomass burning emissions from 1997 to 2004, Atmos. Chem. Phys., 6, 3423-3441, doi:10.5194/acp-6-3423-2006, 2006.

Van Wilgen, B. W., Govender, N., Biggs, H. C., Ntsala, D., and Funda, X. N.: Response of Savanna fire regimes to changing firemanagement policies in a large African National Park, Conserv. Biol., 18, 1533-1540, 2004.

Venevsky, S., Thonicke, K., Sitch, S., and Cramer, W.: Simulating fire regimes in human-dominated ecosystems: Iberian Peninsula case study, Glob. Change Biol., 8, 984-998, 2002.

Williams, C. A., Hanan, N. P., Neff, J. C., Scholes, R. J., Berry, J. A., Denning, A. S., and Baker, D. F.: Africa and the global carbon cycle, Carbon Balance and Management, 2(3), doi:10.1186/1750-0680-2-3, 2007. 